\title{
Experimental Investigation of Thermal Characteristics of Kiwira Coal Waste with Rice Husk Blends for Gasification
}

\author{
Deodatus Kazawadi, ${ }^{1}$ Geoffrey R. John, ${ }^{2}$ and Cecil K. King'ondu' ${ }^{1}$ \\ ${ }^{1}$ Department of Sustainable Energy Science and Engineering, The Nelson Mandela African Institution of Science and Technology, \\ P.O. Box 447, Arusha, Tanzania \\ ${ }^{2}$ Department of Mechanical and Industrial Engineering, The University of Dar es Salaam, P.O. Box 35131, Dar es Salaam, Tanzania
}

Correspondence should be addressed to Deodatus Kazawadi; kazawadid@nm-aist.ac.tz

Received 30 July 2014; Revised 9 November 2014; Accepted 9 November 2014; Published 19 November 2014

Academic Editor: S. Venkata Mohan

Copyright (C) 2014 Deodatus Kazawadi et al. This is an open access article distributed under the Creative Commons Attribution License, which permits unrestricted use, distribution, and reproduction in any medium, provided the original work is properly cited.

\begin{abstract}
Eminent depletion of fossil fuels and environmental pollution are the key forces driving the implementation cofiring of fossil fuels and biomass. Cogasification as a technology is known to have advantages of low cost, high energy recovery, and environmental friendliness. The performance/efficiency of this energy recovery process substantially depends on thermal properties of the fuel. This paper presents experimental study of thermal behavior of Kiwira coal waste/rice husks blends. Compositions of 0 , 20, 40, 60,80 , and $100 \%$ weight percentage rice husk were studied using thermogravimetric analyzer at the heating rate of $10 \mathrm{~K} / \mathrm{min}$ to $1273 \mathrm{~K}$. Specifically, degradation rate, conversion rate, and kinetic parameters have been studied. Thermal stability of coal waste was found to be higher than that of rice husks. In addition, thermal stability of coal waste/rice husk blend was found to decrease with an increase of rice husks. In contrast, both the degradation and devolatilization rates increased with the amount of rice husk. On the other hand, the activation energy dramatically reduced from $131 \mathrm{~kJ} / \mathrm{mol}$ at $0 \%$ rice husks to $75 \mathrm{~kJ} / \mathrm{mol}$ at $100 \%$ rice husks. The reduction of activation energy is advantageous as it can be used to design efficient performance and cost effective cogasification process.
\end{abstract}

\section{Introduction}

The ever increasing need for clean energy, environmental protection, and alternative use of fossil fuel has necessitated the recovery of energy from waste fossil energy resources. Efficient ways to recover damped coal waste are on record and range from circulating fluidized bed combustor to gasification and pyrolysis [1].

Tanzania has approximately 1.5 billion metric tons of proven coal [2] with Kiwira coal mine having a proven deposit of 4 million metric tons [3]. It has an annual coal waste production of 17,374 tons [4] and has damped over 500,000 metric tons of waste for the 2 million metric tons of coal already mined. Although Tanzania has reasonably enough unutilized fresh coal, effective use of coal waste can provide sustainable profile of fossil fuel use.

Tanzania has a wide range of biomass including forestry and agricultural residue. Rice husk in Tanzania is not used efficiently and as such most of it is wasted. For example, Mhilu estimated 326,220 tons of rice husks are wasted annually compared to 10,400 tons of coffee husks [5].

Direct combustion of coal waste has a wide range of constraints from environmental pollution, low energy recovery, and high cost [1]. Proven, cheap, and environmental friendly technologies such as gasification/cogasification [6] are suitable for the utilization of these materials. The technology to incorporate renewable resources into fossil fuels especially biomass for energy recovery is on increase. Researches on cogasification of coal and biomass have shown advantages ranging from economic benefit to environmental friendly and increased energy recovery $[7,8]$. The utilization of these technologies in Tanzania can be an alternative for sustainable energy supply especially for the utilization of coal waste.

It has been shown that coal/coal waste-biomass blends not only reduce pollution especially carbon dioxide but also increase the recovery during gasification due to 
the catalytic nature of inorganic minerals in the biomass and reduction in operating temperature [8,9]. Although cogasification of coal and biomass has not been put in place at large scale [10] it is nevertheless a promising technology [11].

Biomass is a promising energy source due to its abundance [12]. The report on biomass potential in Africa predicted that, in 2020, up to $13900 \mathrm{PJ} / \mathrm{yr}$ from crops, $5400 \mathrm{PJ} / \mathrm{yr}$ from forests, and $5254 \mathrm{PJ} / \mathrm{yr}$ from wastes will be available [13]. Utilizing biomass with coal waste will increase the downstream use of renewable energy sources in the energy systems.

Biomass and coal waste, however, have different chemical and physical properties, such as volatile matter, ash content, composition, density, and calorific value [14]. These differences in the properties lead to different reactivity and thermal characteristics during thermochemical processes. For example, biomass gasification occurs at low temperature than coal, thus reducing heat loss, emission, and material problems associated with high temperature [15]. Blending of coal waste and biomass can reduce gasification temperature [7].

Earlier studies on thermal behavior of biomass and coal are on record. Bhagavatula et al. [16] studied thermal performance of Montana coal and corn stover blends and found that increasing biomass reduced reaction temperature. The study done by Magdziarz and Wilk [17] on coal, sewage, and biomass indicated that the temperature of maximum loss increased with addition of $90 \%$ of coal. Furthermore, other studies have shown coal biomass blends to have higher reactivity compared to coal alone due to high volatile matter [18].

Thermal behavior of Tanzanian coal waste and biomass is not on record to date [19]. This coupled with the huge abundance of coal waste and biomass in Tanzania provides the stimulus to undertake studies related to thermal characteristics of coal waste/biomass blends for energy recovery. The aim of this paper is therefore to provide data that can be used for the design of an effective and environment friendly cogasification process for the recovery of energy from coal wastes/rice husk blends. To achieve this, it is imperative to determine the reaction rate conditions and maximum gasification temperature and to understand thermal decomposition mechanisms [20].

\section{Methodology}

2.1. Sample Collection and Preparation. Coal waste samples were randomly sampled from Kiwira coal waste dump. Rice husk samples were randomly obtained from rice mill wastes in Dodoma.

The samples were ground to less than $2 \mathrm{~mm}$ in order to limit the effect of interparticle heat transfer [16]. The samples mass were measured on beam balance to make the blends with composition by weight percent of $0,20,40,60,80$, and $100 \%$ rice husk. Homogeneity was obtained by thorough mixing. The selection of the above blends was to ensure that the study covered a reasonable range of blend.
2.2. Experiment Carryout. Each sample was analyzed in triplicate and standard errors are calculated using (2):

$$
\begin{gathered}
S_{r}=\sqrt{\frac{1}{(n-1)} \sum_{i=1}^{n}\left(x_{i}-\bar{x}\right)^{2}}, \\
\operatorname{Se}=\frac{S_{r}}{\sqrt{n}},
\end{gathered}
$$

where $x_{i}$ is experiment $i$ data, $\bar{x}$ is mean, $n$ is the number of experiments, $S_{r}$ is standard deviation, and Se is standard error.

2.3. Proximate and Ultimate Analysis. Proximate analysis was done by standard method ASTM 3172 in the furnace. The calorific values were determined by ASTM D4809 standard method in a bomb calorimeter.

Determination of carbon, hydrogen, nitrogen, and sulfur was done by ASTM (E775, E777, and E778) standards methods. Oxygen was determined by difference, where the sum of ash, carbon, hydrogen, sulphur, and nitrogen was subtracted from $100 \%$ [21].

2.4. Thermogravimetric Analysis. Thermogravimetric (TG) analysis is one of the thermal analysis techniques used to measure the mass change, thermal decomposition, and thermal stability of materials. Overall kinetics can be easily obtained by measuring the change in mass of a sample with time based on isothermal or nonisothermal thermogravimetric data [22].

Thermal stability of blends was studied under inert nitrogen condition using a simultaneous thermal gravimetric analyzer type NETZSCH STA PC Luxx TG. Nitrogen (99.95\% purity) was used as the carrier gas controlled by gas flow meter at a flow rate of $60 \mathrm{~mL} / \mathrm{min}$ and pressure of 0.5 bars to avoid unwanted oxidation. In the STA 409 PC Luxx TG, Preteus software was used to acquire, store, and analyze data in desktop computer.

The samples were dried at $100^{\circ} \mathrm{C}$ temperature for $24 \mathrm{~h}$ to remove moisture. $30 \mathrm{mg}$ of the samples of particle size less than $2 \mathrm{~mm}$ were placed on a crucible and heated from 35 to $1000^{\circ} \mathrm{C}$ at constant heating rate of $10 \mathrm{~K} / \mathrm{min}$. The low heating rate was used in expectations of allowing the reactions to reach equilibrium [23].

2.5. Kinetics of Thermal Degradation. Parameters that describe kinetics considered were activation energy and preexponential factor. Activation energy is defined as the height of energy barrier which has to be overcome by relative translation motion of the reactants for a reaction to occur [24]. The activation energy indicates how much energy must be absorbed by reactant to start the reaction [25]. Higher activation means the rate of reaction depends strongly on temperature.

2.5.1. Theoretical Approach. Pyrolysis process of a solid can generally be described as

$$
A_{\text {solid }} \longrightarrow B_{\text {solid }}+C_{\text {volatile }}
$$

where volatile is the sum of gas and tar. 
The degree of conversion $\alpha$ of a material is defined as

$$
\alpha=\frac{W_{o}-W_{t}}{W_{o}-W_{f}}
$$

where $W_{o}$ is the original mass, $W_{f}$ is the final mass, and $W_{t}$ is the mass at time $t$. [26]

Rate of degradation of a material is expressed by a way of

$$
\frac{d \alpha}{d t}=k(T) *(1-\alpha)^{n},
$$

where $n$ is the order of reaction, $\alpha$ is the degree of conversion, and $k(T)$ is the rate constant of reaction whose temperature dependence is expressed by the Arrhenius equation,

$$
k(T)=A \operatorname{Exp}^{(-E / R T)},
$$

where $E$ is the activation energy in $\mathrm{kJ} / \mathrm{mole}, T$ is temperature in $\mathrm{K}, R$ is the universal gas constant $(8.314 \mathrm{~J} / \mathrm{Kmol})$, and $A$ is the preexponential factor $\left(\mathrm{min}^{-1}\right)$.

For pyrolysis and oxidation reactions under nonisothermal conditions, the heating rate plays a very important role in determining the kinetic parameters. Low heating rate means that a reaction is closer to equilibrium and vice versa [26,27].

Many authors have approximated the overall process as a first-order decomposition occurring uniformly throughout the coal and biomass particles [28-30]. For a first-order reaction at constant heating rate

$$
\beta=\frac{d T}{d t} .
$$

Equation (5) is transformed to

$$
\frac{d \alpha}{d T}=\left[A \frac{(1-\alpha)}{\beta}\right] \exp \left(\frac{-E}{R T}\right) .
$$

Integration of the above equation subject to the condition that conversion is zero at initial temperature, $T_{0}$, leads to

$$
\ln [1-\alpha]=-\frac{A}{\beta} \int_{T_{o}}^{T} \operatorname{Exp}^{(-E / R T)} d T .
$$

Since there is no conversion at initial temperature, $T_{0}$, the limits of the integral become

$$
\int_{0}^{T} \operatorname{Exp}\left(\frac{-E}{R T}\right) .
$$

Introducing a new function

$$
f(y)=\int_{y}^{\infty} \frac{e^{-y}}{y^{2}} d y
$$

where $y$ is $-E / R T$, (9) becomes

$$
\ln (1-\alpha)=\frac{-A}{\beta} f(y) .
$$

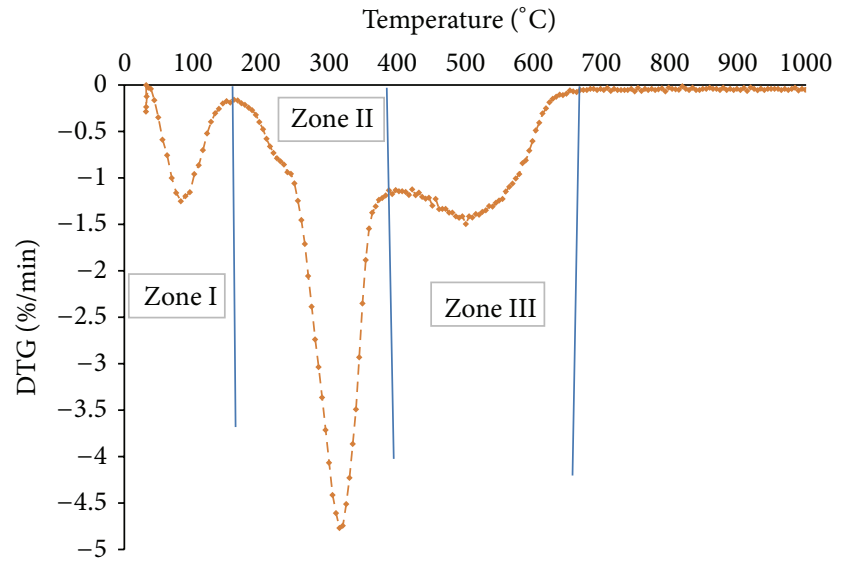

FIGURE 1: DTG results showing reaction steps of rice husk.

The Coats-Redfern approximation method was deployed in this study to determine the approximate value of temperature integral. This method was chosen because it provides the best linearity of the data as opposed to other analytical modelfitting methods $[27,31,32]$.

When this method is used, (11) yields

$$
f(y) \approx \frac{e^{-y}}{y^{2}}(1-y) .
$$

Equation (8) is rearranged to result in

$$
\ln \left[\frac{-\ln (1-\alpha)}{T^{2}}\right]=\ln \left[\frac{A R}{H E}\left(1-\frac{2 R T}{E}\right)\right]-\frac{E}{R T} .
$$

Equation (13) is written in the form $y=a x+b$, where

$$
a=-\frac{E}{R}, \quad b=\ln \left[\frac{A R}{H E}\left(1-\frac{2 R T}{E}\right)\right] .
$$

The temperature in the intercept value " $b$ " is obtained by averaging the initial and final mass remaining for a specific reaction step. The obtained value corresponds to the temperature value to be used:

$$
W_{T}=\frac{\left(W_{o}+W_{f}\right)}{2} .
$$

Reaction steps considered are moisture removal (Zone I), volatile removal (Zone II), and char pyrolysis (Zone III) as indicated in Figure 1. In each reaction step, degree of conversion is recalculation. For each step of reaction, $E$ and $A$ can be calculated using (14).

\section{Results and Discussion}

3.1. Proximate and Ultimate Analysis. Proximate and ultimate results are shown in Table 1. Coal waste was found to have high ash content and low volatile matter compared to rice husks and their corresponding blends. High ash content of coal waste leads to high thermal stability. 
TABLE 1: Proximate and ultimate results.

\begin{tabular}{cccc}
\hline Sample & & Kiwira coal waste & Rice husks \\
\hline Moisture content (\%) & & $3.26 \pm 0.04$ & $7.2 \pm 0.02$ \\
& VM & $16.84 \pm 0.21$ & $59.59 \pm 0.43$ \\
Proximate, \% dry basis & FC & $19.23 \pm 0.77$ & $17.29 \pm 0.45$ \\
& Ash & $63.93 \pm 0.57$ & $23.12 \pm 0.06$ \\
\hline & $\mathrm{C}$ & $19.68 \pm 0.33$ & $38.13 \pm 0.12$ \\
& $\mathrm{H}$ & $2.07 \pm 0.03$ & $4.59 \pm 0.005$ \\
Proximate, \% dry basis & $\mathrm{O}$ & $12.89 \pm 0.36$ & $33.10 \pm 0.08$ \\
& $\mathrm{Cl}$ & $\mathrm{NIL}$ & $0.31 \pm 0.002$ \\
& $\mathrm{~S}$ & $1.00 \pm 0.04$ & $0.06 \pm 0.003$ \\
& $\mathrm{~N}$ & $0.43 \pm 0.01$ & $0.68 \pm 0.032$ \\
\hline HHV MJ/kg daf & & $22.0 \pm 0.35$ & $19.6 \pm 0.04$ \\
\hline
\end{tabular}

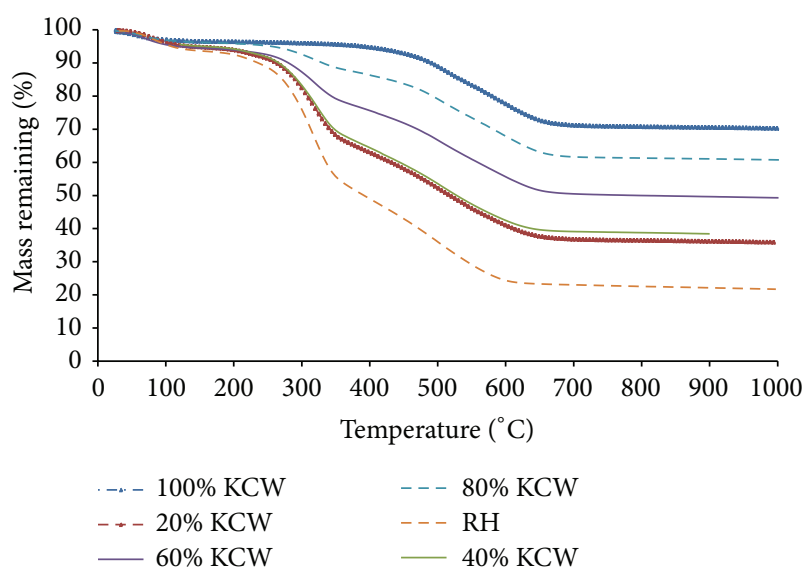

FIGURE 2: TG analysis results of Kiwira coal waste/rice husk blends.

3.2. Thermogravimetric (TG) Analysis Results. The TG weight loss curves of the blends in a nonisothermal heating at heating rate of $10 \mathrm{~K} / \mathrm{min}$ are shown in Figure 2.

Weight loss profiles of blends are between the two profiles of coal waste and rice husk. The results showed that rice husk is more reactive than coal waste. This is in agreement with the work of Zakaria et al. [33] which showed that rice husk is more reactive than coal during pyrolysis and combustion. This is due to the fact that coal waste, unlike rice husk, has high ash contents, since it contains thermally stable components like silica.

The results also showed that, as rice husk content increased, temperature of pyrolysis decreased. For example, for pure coal waste, the pyrolysis temperature was about $760^{\circ} \mathrm{C}$ while that of $40 \%$ coal waste/rice husk blend and pure rice husk was about 690 and $650^{\circ} \mathrm{C}$, respectively, as shown in Figures 3, 4, and 5.

Coal is considered as a complex polymer network consisting of aromatic clusters of aliphatic bridge [16]. Duration of evolution of volatiles (that end up producing $\mathrm{CO}, \mathrm{H}_{2}, \mathrm{CH}_{4}$, and $\mathrm{H}_{2} \mathrm{O}$ ) is relatively shorter for biomass than coal $[34,35]$. The decrease in thermal stability with increase in rice husk content could be useful in designing cheap thermochemical conversion (e.g., gasification) processes.

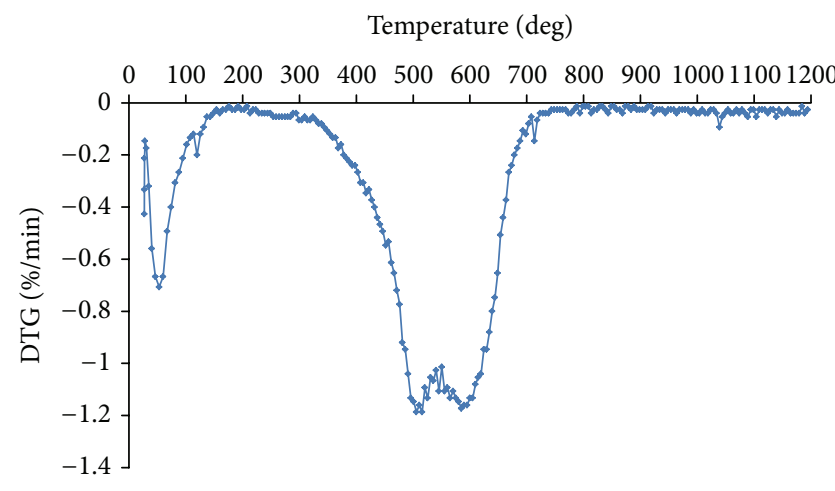

FIGURE 3: DTG results of Kiwira coal waste.

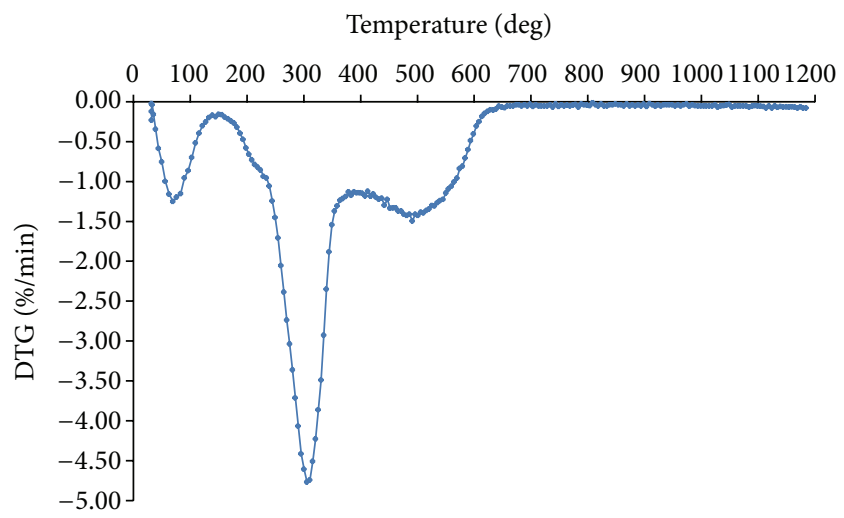

FIGURE 4: DTG results of rice husk.

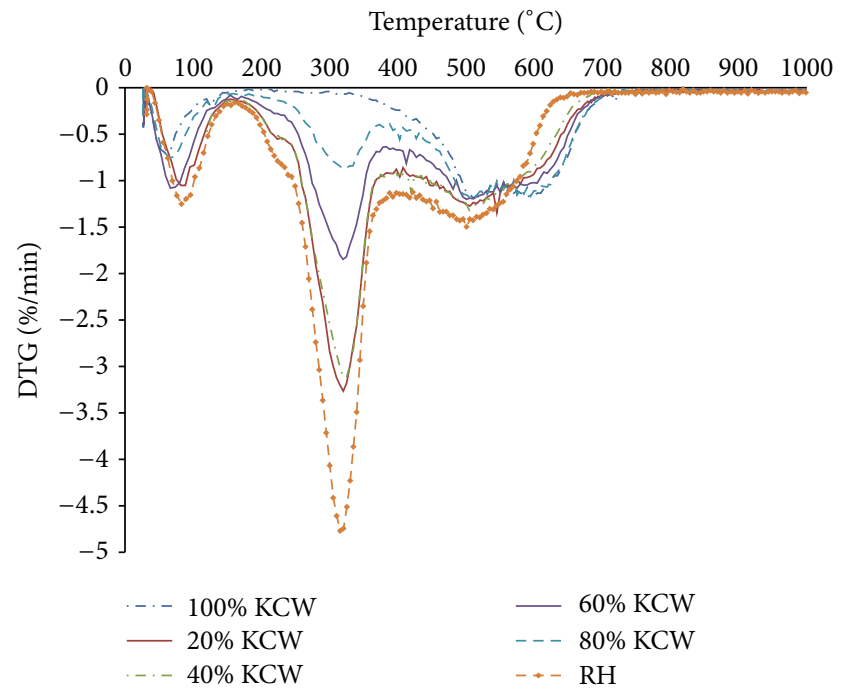

FIGURE 5: DTG profiles of Kiwira coal waste/rice husk blends.

3.3. Differential Thermogravimetric (DTG) Analysis Results. Figures 3-5 show the DTG profiles of coal waste, rice husk, and their corresponding blends at heating rate of $10 \mathrm{~K} / \mathrm{min}$ in nonisothermal conditions. Three clear zones were observed that can be grouped as shown in Figure 1. These zones are useful for comparing different materials in terms of 
TABLE 2: Zones of reactions of blends.

\begin{tabular}{|c|c|c|c|c|}
\hline \multirow[b]{2}{*}{ Blend } & \multicolumn{2}{|c|}{ Devolatilization } & \multicolumn{2}{|c|}{ Char combustion } \\
\hline & $\begin{array}{l}\text { Temperature } \\
\text { range }\left({ }^{\circ} \mathrm{C}\right)\end{array}$ & $\begin{array}{l}\text { Maximum } \\
\text { peak } \\
(\% / \mathrm{min})\end{array}$ & $\begin{array}{l}\text { Temperature } \\
\text { range }\left({ }^{\circ} \mathrm{C}\right)\end{array}$ & $\begin{array}{c}\text { Maximum } \\
\text { peak } \\
(\% / \mathrm{min})\end{array}$ \\
\hline Coal waste & $300-560$ & 1.2 & $560-760$ & 1.2 \\
\hline 20 & $160-390$ & 3.3 & $390-670$ & 1.3 \\
\hline 40 & $160-400$ & 3.1 & $400-690$ & 1.3 \\
\hline 60 & $160-400$ & 1.9 & $400-720$ & 1.2 \\
\hline 80 & $170-400$ & 0.9 & $400-730$ & 1.2 \\
\hline Rice husk & $160-380$ & 4.8 & $400-650$ & 1.4 \\
\hline
\end{tabular}

composition and measuring the fuel reactivity [36, 37]. For example, the material with high range of char degradation means that the material has high fixed carbon. Coal waste has been shown to have high fixed carbon by proximate analysis.

Each sample showed a first peak which corresponds to moisture removal [38]. This peak occurred at temperature less than $200^{\circ} \mathrm{C}$. Second and third profiles represent devolatilization and char combustion, respectively. Devolatilization in coal waste occurred at higher temperature than that in rice husk and coal waste/rice husk blends. For coal waste, devolatilization and char combustion profiles occurred close to each other. Gil et al. observed only one profile for both devolatilization and char combustion on coal [39].

Table 2 reports temperature ranges for devolatilization and char pyrolysis stages. Rice husk devolatilization occurred between 160 and $380^{\circ} \mathrm{C}$. This range is similar to the one reported for the pyrolysis of rice husk hemicelluloses and cellulose [33]. Coal waste devolatilization occurred at temperatures $\left(300-560^{\circ} \mathrm{C}\right)$ higher than those of rice husk. The coal waste devolatilization temperature range obtained was comparable to that of coal $\left(415-520^{\circ} \mathrm{C}\right)$ reported by Zakaria et al. [33]. Char combustion for coal waste has been seen to be higher than rice [33]. This is attributed to the high fixed carbon context in coal wastes. In our study, rice husk char was completely degraded at $650^{\circ} \mathrm{C}$ while coal waste degraded at $760^{\circ} \mathrm{C}$. Rice husk char degradation temperature $\left(650^{\circ} \mathrm{C}\right)$ obtained in our work is comparable to $600^{\circ} \mathrm{C}$ reported rice husk char by Sonobe et al. [40].

Degradation rate increased with increase in rice husk. This was attributed to reactivity of rice husk (biomass). The presence of rice husks promotes the production of volatiles in coal waste/rice husk blends. This phenomenon was also reported by Haykiri-Acma and Yaman [41]. Devolatilization and char combustion temperatures decreased with increase in rice husk. Degradation peak values increased with an increase in rice husk. This is attributed to the reactivity of rice husk which is higher than that of coal waste due to increase in volatile matter in biomass [16].

The temperature band width of reaction decreased with increase in rice husk due to the increase in volatile matter and decrease in fixed carbon leading to increased reactivity of the blend. The bond strength of coal waste can also be a reason for increased reaction temperature band width with increasing in coal waste. Coal has been reported to have a high bond energy

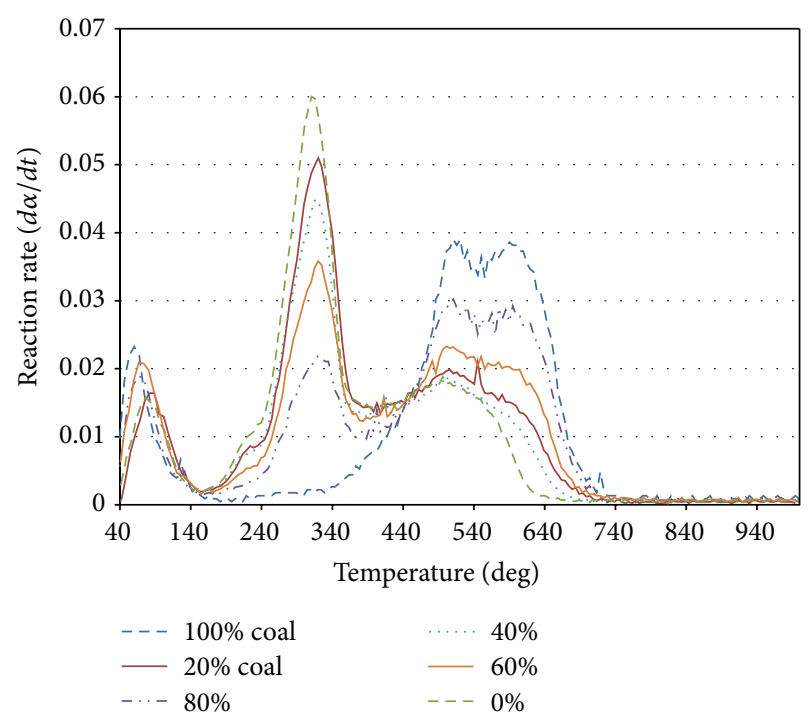

FIGURE 6: Conversion rates of Kiwira coal waste/rice husk biomass blends.

of about $1000 \mathrm{~kJ} / \mathrm{mol}$ [42] compared to biomass with bond energy around $380-420 \mathrm{~kJ} / \mathrm{mol}$ [43]. This means degradation rate will increase with increase in rice husk content.

3.4. Conversion Rate. Figure 6 shows the rate of conversion of different blends. It can be observed that, at devolatilization stage, the rate of conversion increased with increase in rice husk content. This is attributed to the reactivity of volatile matter in rice husk content. Conversion rate of char increased with increase in coal waste. This is attributed to the increase in fixed carbon with increasing coal waste.

Devolatilization rate increased with increase in rice husk content. It is known that volatile matter leads to production of tar which is not needed in the syngas [35]. Blending coal waste and rice husk may reduce production of tar; however this may be accompanied by the reduction in the rate of conversion.

High conversion rate of devolatilization occurred at around $320^{\circ} \mathrm{C}$ while for char degradation it occurs at $500^{\circ} \mathrm{C}$. High reaction rate of devolatilization with increase in rice husk content can be explained by devolatilization behavior of most biomass fuels. Biomass contains reactive components responsible for initial steps of devolatilization. Final tail of devolatilization, which is the decomposition of lignin and mainly produces char, is suggested to be caused by the less reactive structure of the remaining solid after main pyrolysis [44].

3.5. Kinetics Parameters Results. The kinetic properties, activation energy and preexponential factor, have been calculated using (14). Table 3 shows the calculated results of kinetic parameters of the blends.

The activation energy for devolatilization was found to increase with increase in rice husk. The results indicated that activation increased from 51 to 85 for $100 \%$ coal to $0 \%$ coal, respectively. This was due to the increase in volatile matters. 
TABLE 3: Kinetic properties of Kiwira coal waste/rice husk blends.

\begin{tabular}{|c|c|c|c|c|}
\hline \multirow{3}{*}{$\begin{array}{l}\text { Blend } \\
\text { (\% coal) }\end{array}$} & \multicolumn{4}{|c|}{ Degradation step } \\
\hline & \multicolumn{2}{|c|}{ Volatilization } & \multicolumn{2}{|c|}{ Char combustion } \\
\hline & $E(\mathrm{~kJ} / \mathrm{mol})$ & $A\left(\min ^{-1}\right)$ & $E(\mathrm{~kJ} / \mathrm{mol})$ & $A\left(\min ^{-1}\right)$ \\
\hline 100 & $51.34 \pm 0.75$ & $347 \pm 7.0$ & $131.02 \pm 1.6$ & $7.7 \pm 0.2 E 6$ \\
\hline 80 & $58.89 \pm 0.44$ & $2.8 \pm 0.12 E 4$ & $83.35 \pm 0.27$ & $3.9 \pm 0.9 E 4$ \\
\hline 60 & $59.43 \pm 0.19$ & $3.8 \pm 0.45 E 4$ & $81.09 \pm 0.25$ & $3.4 \pm 1 E 4$ \\
\hline 40 & $60.60 \pm 0.20$ & $3.9 \pm 0.12 E 4$ & $78.63 \pm 0.67$ & $5.4 \pm 2.8 E 4$ \\
\hline 20 & $63.70 \pm 0.9$ & $8.8 \pm 0.7 E 4$ & $76.51 \pm 0.7$ & $6.6 \pm 1.2 E 4$ \\
\hline 0 & $84.9 \pm 0.5$ & $1.5 \pm 0.2 E 4$ & $75.14 \pm 0.92$ & $1.2 \pm 0.75 E 4$ \\
\hline
\end{tabular}

In char combustion step, the activation energy was observed to increase with increase in coal waste, ranging from 131 to $75 \mathrm{~kJ} / \mathrm{mol}$ for $100 \%$ coal to $0 \%$ coal, respectively. This was attributed to the high content of fixed carbon in coal waste than that in rice husk. Smaller values of average activation energy mean a more reactive solid, while larger values mean a less reactive solid [20]. This means coal wastes have char which is less reactive.

Overall activation energy at char combustion stage decreased with increase in rice husk. This is attributed to weak bonds in rice husk than that in coal waste [45]. This shows that rice husk/coal waste blends proceed at low energy than coal waste alone. This favors gasification of blends than that of coal waste alone.

\section{Conclusions}

Thermogravimetric analysis has been performed on Kiwira coal waste/rice husk blends aiming at establishing data for cogasification for syngas production. The kinetic parameters have been calculated using multistep first-order reaction at $10 \mathrm{~K} / \mathrm{min}$ heating rate. The following information has been obtained which is essential to design cogasification process.

(1) Thermal stability of coal waste is high and decreases with increase in rice husk. Blending of coal waste and rice husk may reduce thermal stability of coal waste and thus offer designing economic and environmental friendly thermochemical recovery method.

(2) Increase in degradation rate with increases in rice husk shows the reactivity of rice husk. This also favors thermochemical process to recover energy from coal waste.

(3) Activation energy in char pyrolysis zone has decreased with increase in rice husk: $131-75 \mathrm{~kJ} / \mathrm{mol}$. This is associated with decrease in the fixed carbon of blend with increase in rice husk.

(4) The overall activation energy of pyrolysis of blends has decreased with increase in rice husk, 131$85 \mathrm{~kJ} / \mathrm{mole}$. Decrease in activation indicates that operating temperature also decreases. This shows that gasification of blends occurs at low temperature than is coal waste alone. This is advantageous to reduce pollutants production that depends on high temperature, such as $\mathrm{NO}_{x}$.

(5) Cogasification to recover energy from coal waste is a breakthrough technology favoured by decreasing operating temperature with blending technique.

The study has shown that, using blending technique, thermal stability and activation energy properties of coal waste/rice husk blends have been reduced by increasing rice husk. Thermochemical energy recovery process can be undertaken at low temperature compared to coal waste alone. The use of low temperature process minimizes construction material cost and reduces pollutants formation. With these data obtained it is expected that cogasification of coal waste and rice husk is less costly and releases less pollutants when compared to coal waste gasification alone.

\section{Nomenclature}

$\begin{array}{ll}\text { KCW: } & \text { Kiwira coal waste } \\ \text { RH: } & \text { Rice husk } \\ \text { TG: } & \text { Thermogravimetric } \\ \text { DTG: } & \text { Differential thermogravimetric } \\ \text { NM-AIST: } & \text { Nelson Mandela African Institution of } \\ & \text { Science and Technology } \\ \text { COSTECH: } & \text { Commission for Science and } \\ & \text { Technology. }\end{array}$

\section{Conflict of Interests}

The authors declare that there is no conflict of interests regarding the publication of this paper.

\section{Acknowledgments}

The authors sincerely appreciate the support provided by NM-AIST and COSTECH. Appreciation is also extended to the Administration of Kiwira Coal Mine for providing access in obtaining the samples. Sincere thanks are also extended to the University of Dar es Salaam for allowing the access of its laboratories and providing necessary support.

\section{References}

[1] S. Su, Y. G. Jin, X. X. Yu, and R. Worrall, "Preliminary experimental studies of waste coal gasification," in Cleaner Combustion and Sustainable World, pp. 719-723, Springer, 2013.

[2] TMAA, "Minerals Found in Tanzania-Coal," 2014, http://www.tmaa.go.tz/minerals/view/coal.

[3] Ministry of Energy and Minerals, Power System Master Plan 2012 Update, Ministry of Energy and Minerals, Dar es Salaam, Tanzania, 2012.

[4] D. A. Mwakipesile, P. L. Mtui, I. S. N. Mkilaha, and M. H. Mkumbwa, "Behaviour of trace metals in gasification of Kiwira coal wastes," in Proceedings of the International Conference Mechanical and Industrial Engineering, pp. 269-273, Arusha, Tanzania, 2012.

[5] C. F. Mhilu, "Analysis of energy characteristics of rice and coffee husks blends," ISRN Chemical Engineering, vol. 2014, Article ID 196103, 6 pages, 2014. 
[6] M. H. Lapuerta, J. J. Hernández, A. Pazo, and J. López, "Gasification and co-gasification of biomass wastes: effect of the biomass origin and the gasifier operating conditions," Fuel Processing Technology, vol. 89, no. 9, pp. 828-837, 2008.

[7] Y. G. Pan, E. Velo, X. Roca, J. J. Manya, and L. Puigjaner, "Fluidized-bed co-gasification of residual biomass/poor coal blends for fuel gas production," Fuel, vol. 79, no. 11, pp. 13171326, 2000.

[8] J. J. Hernández, G. Aranda-Almansa, and C. Serrano, "Cogasification of biomass wastes and coal-coke blends in an entrained flow gasifier: an experimental study," Energy and Fuels, vol. 24, no. 4, pp. 2479-2488, 2010.

[9] M. W. Seo, J. H. Goo, S. D. Kim, S. H. Lee, and Y. C. Choi, "Gasification characteristics of coal/biomass blend in a dual circulating fluidized bed reactor," Energy and Fuels, vol. 24, no. 5, pp. 3108-3118, 2010.

[10] G. Gordillo, K. Annamalai, and N. Carlin, "Adiabatic fixed-bed gasification of coal, dairy biomass, and feedlot biomass using an air-steam mixture as an oxidizing agent," Renewable Energy, vol. 34, no. 12, pp. 2789-2797, 2009.

[11] N. Koukouzas, A. Katsiadakis, E. Karlopoulos, and E. Kakaras, "Co-gasification of solid waste and lignite-a case study for Western Macedonia," Waste Management, vol. 28, no. 7, pp. 1263-1275, 2008.

[12] C. B. Field, J. E. Campbell, and D. B. Lobell, "Biomass energy: the scale of the potential resource," Trends in Ecology and Evolution, vol. 23, no. 2, pp. 65-72, 2008.

[13] K. Stecher, A. Brosowski, and D. Thrän, Biomass Potential in Africa, IRENA-DBFZ, Abu Dhabi, United Arab Emirates, 2013.

[14] P. Molcan, G. Lu, T. L. Bris, Y. Yan, B. Taupin, and S. Caillat, "Characterisation of biomass and coal co-firing on a 3 MWth Combustion Test Facility using flame imaging and gas/ash sampling techniques," Fuel, vol. 88, no. 12, pp. 2328-2334, 2009.

[15] A. Kumar, D. D. Jones, and M. A. Hanna, "Thermochemical biomass gasification: a review of the current status of the technology," Energies, vol. 2, no. 3, pp. 556-581, 2009.

[16] A. Bhagavatula, G. Huffman, N. Shah, and R. Honaker, "Evaluation of thermal evolution profiles and estimation of kinetic parameters for pyrolysis of coal/corn stover blends using thermogravimetric analysis," Journal of Fuels, vol. 2014, Article ID 914856, 12 pages, 2014.

[17] A. Magdziarz and M. Wilk, "Thermal characteristics of the combustion process of biomass and sewage sludge," Journal of Thermal Analysis and Calorimetry, vol. 114, no. 2, pp. 519-529, 2013.

[18] P. Wang, S. Hedges, K. Casleton, and C. Guenther, "Thermal behavior of coal and biomass blends in inert and oxidizing gaseous environments," International Journal of Clean Coal and Energy, vol. 1, pp. 35-42, 2012.

[19] L. Wilson and H. Iddi, Scientific and Technical Cooperation between Tanzania Industrial Research and Development Organization (TIRDO) of Tanzania and the Council of Science and Industrial Research (CSIR) of India, TIRDO, 2014.

[20] E. Biagini, A. Fantei, and L. Tognotti, "Effect of the heating rate on the devolatilization of biomass residues," Thermochimica Acta, vol. 472, no. 1-2, pp. 55-63, 2008.

[21] A. Volborth, G. E. Miller, C. K. Garner, and P. A. Jerabek, "Oxygen determination and stoichiometry of some coals," in Proceedings of the American Chemical Society Meeting, Division of Fuel Chemistry, Chicago, Ill, USA, 1977.
[22] S. C. Turmanova, S. D. Genieva, A. S. Dimitrova, and L. T. Vlaev, "Non-isothermal degradation kinetics of filled with rise husk ash polypropene composites," Express Polymer Letters, vol. 2, no. 2, pp. 133-146, 2008.

[23] P. J. Haines, Principles of Thermal Analysis and Calorimetry, vol. 30, Royal Society of Chemistry, 2002.

[24] M. Menzinger and R. Wolfgang, "The meaning and use of the Arrhenius activation energy," Angewandte Chemie International Edition, vol. 8, no. 6, pp. 438-444, 1969.

[25] G. Raj, Chemical Kinetics, Krishna Prakashan Media, Uttar Pradesh, India, 8th edition, 2010.

[26] L. Zhou, Y. Wang, Q. Huang, and J. Cai, “Thermogravimetric characteristics and kinetic of plastic and biomass blends copyrolysis," Fuel Processing Technology, vol. 87, no. 11, pp. 963969, 2006.

[27] A. W. Coats and J. P. Redfern, "Kinetic parameters from thermogravimetric data," Nature, vol. 201, no. 4914, pp. 68-69, 1964.

[28] C. Di Blasi, "Modeling chemical and physical processes of wood and biomass pyrolysis," Progress in Energy and Combustion Science, vol. 34, no. 1, pp. 47-90, 2008.

[29] A. K. Sadhukhan, P. Gupta, and R. K. Saha, "Modelling and experimental studies on pyrolysis of biomass particles," Journal of Analytical and Applied Pyrolysis, vol. 81, no. 2, pp. 183-192, 2008.

[30] Y. G. Pan, E. Velo, and L. Puigjaner, "Pyrolysis of blends of biomass with poor coals," Fuel, vol. 75, no. 4, pp. 412-418, 1996.

[31] E. Sima-Ella, G. Yuan, and T. Mays, "A simple kinetic analysis to determine the intrinsic reactivity of coal chars," Fuel, vol. 84, no. 14-15, pp. 1920-1925, 2005.

[32] J. Fermoso, B. Arias, M. V. Gil et al., "Co-gasification of different rank coals with biomass and petroleum coke in a high-pressure reactor for $\mathrm{H}_{2}$-rich gas production," Bioresource Technology, vol. 101, no. 9, pp. 3230-3235, 2010.

[33] Z. M. Zakaria, M. A. Mohd Ishak, M. F. Abdullah, and K. Ismail, "Thermal decomposition study of coals, rice husk, rice husk char and their blends during pyrolysis and combustion via thermogravimetric analysis," International Journal of Chemical Technology, vol. 2, no. 3, pp. 78-87, 2010.

[34] A. K. Sadhukhan, P. Gupta, T. Goyal, and R. K. Saha, "Modelling of pyrolysis of coal-biomass blends using thermogravimetric analysis," Bioresource Technology, vol. 99, no. 17, pp. 8022-8026, 2008.

[35] C. Higman and M. van der Burgt, Gasification, Elsevier Science, New York, NY, USA, 2003.

[36] P. T. Williams and S. Besler, "The pyrolysis of rice husks in a thermogravimetric analyser and static batch reactor," Fuel, vol. 72, no. 2, pp. 151-159, 1993.

[37] K. Raveendran, A. Ganesh, and K. C. Khilar, "Pyrolysis characteristics of biomass and biomass components," Fuel, vol. 75, no. 8, pp. 987-998, 1996.

[38] S. S. Idris, N. A. Rahman, K. Ismail, A. B. Alias, Z. A. Rashid, and M. J. Aris, "Investigation on thermochemical behaviour of low rank Malaysian coal, oil palm biomass and their blends during pyrolysis via thermogravimetric analysis (TGA)," Bioresource Technology, vol. 101, no. 12, pp. 4584-4592, 2010.

[39] M. V. Gil, D. Casal, C. Pevida, J. J. Pis, and F. Rubiera, “Thermal behaviour and kinetics of coal/biomass blends during cocombustion," Bioresource Technology, vol. 101, no. 14, pp. 5601$5608,2010$. 
[40] T. Sonobe, P. Suneerat, and N. Worasuwannarak, "Pyrolysis characteristics of Thai-agricultural residues of rice straw, rice husk, and corncob by TG-MS technique and kinetic analysis," in Proceedings of the 2nd Joint International Conference on "Sustainable Energy and Environment (SEE '06)", Bangkok, Thailand, November 2006.

[41] H. Haykiri-Acma and S. Yaman, "Interaction between biomass and different rank coals during co-pyrolysis," Renewable Energy, vol. 35, no. 1, pp. 288-292, 2010.

[42] J. Cai, Y. Wang, L. Zhou, and Q. Huang, “Thermogravimetric analysis and kinetics of coal/plastic blends during co-pyrolysis in nitrogen atmosphere," Fuel Processing Technology, vol. 89, no. 1, pp. 21-27, 2008.

[43] H. B. Vuthaluru, "Investigations into the pyrolytic behaviour of coal/biomass blends using thermogravimetric analysis," Bioresource Technology, vol. 92, no. 2, pp. 187-195, 2004.

[44] M. Zhang and F. Min, "Pyrolysis characteristics and kinetics of fresh biomass with different initial moisture," in Proceedings of the 41st Annual Conference, Bowling Green, Ky, USA, August 2013.

[45] E. A. Evans and K. Ritchie, "Strength of a weak bond connecting flexible polymer chains," Biophysical Journal, vol. 76, no. 5, pp. 2439-2447, 1999. 


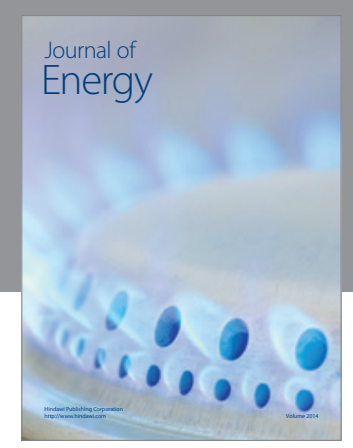

Journal of

Industrial Engineering
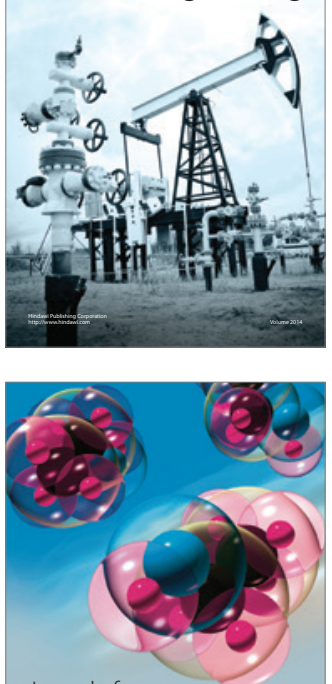

Fuels
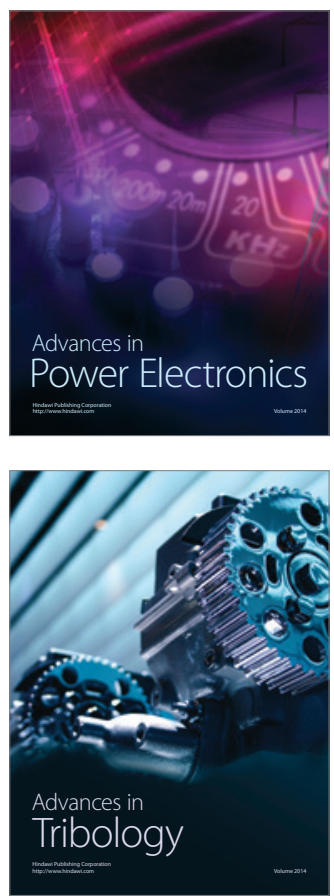

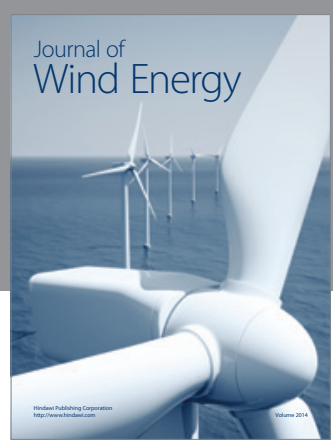

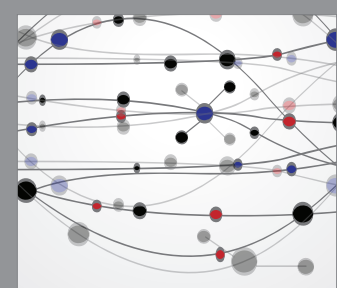

The Scientific World Journal

Submit your manuscripts at http://www.hindawi.com

Journal of

Structures
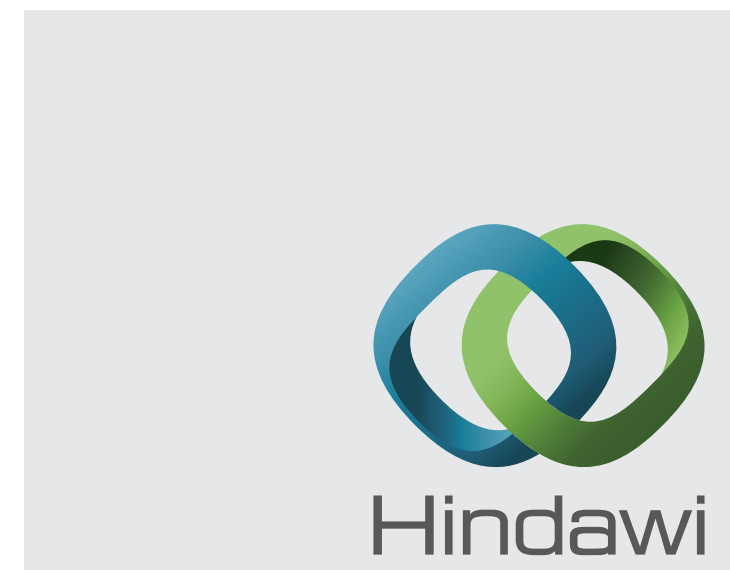

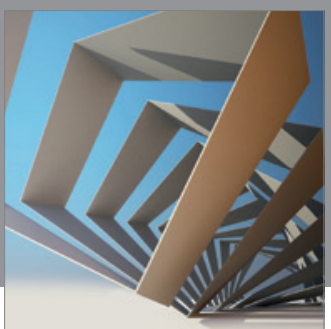

Rotating

Machinery
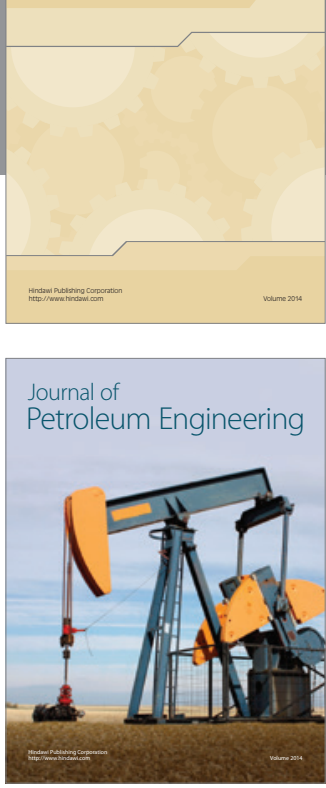

Journal of

Solar Energy
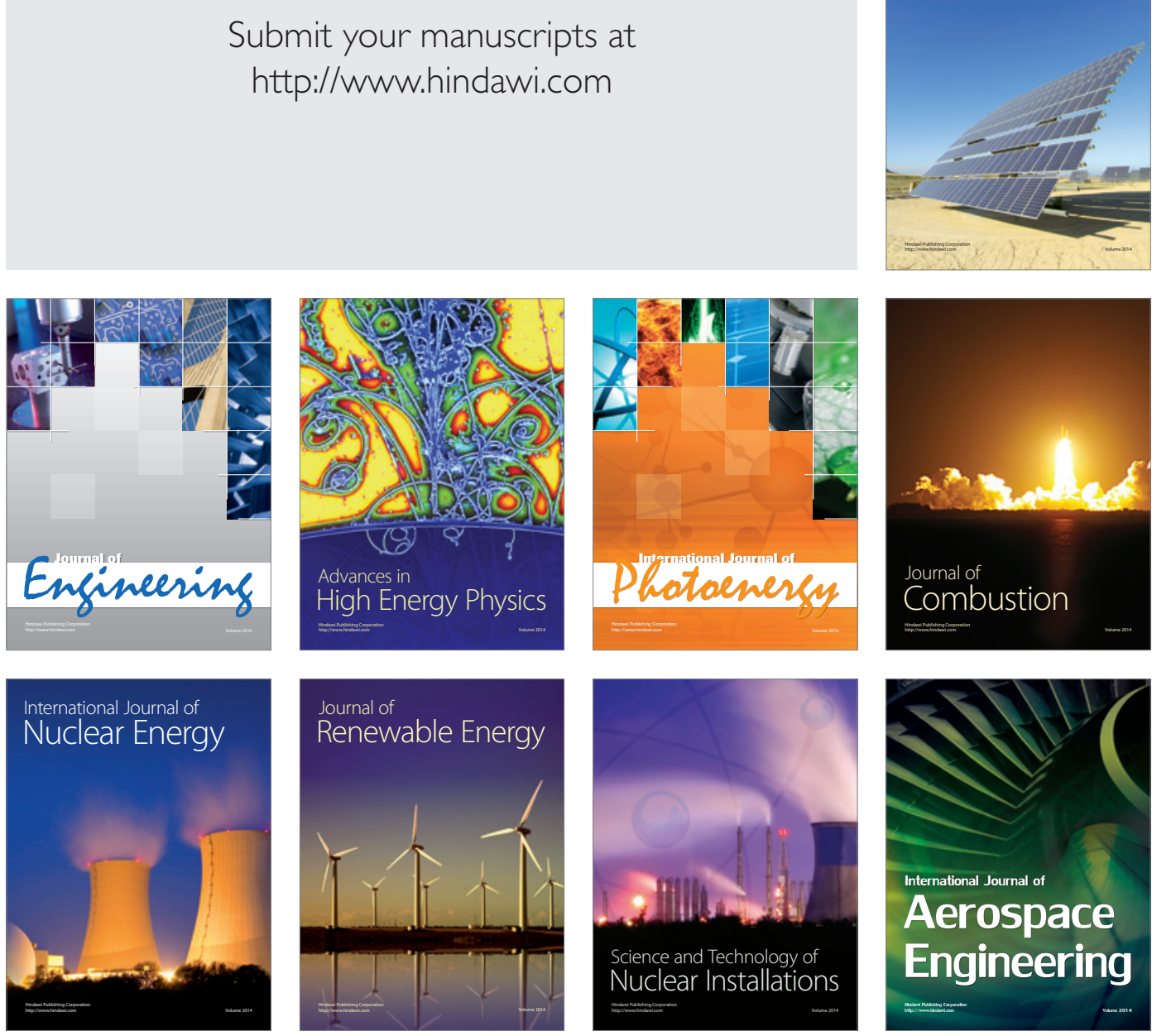